\title{
BMP8B mediates the survival of pancreatic cancer cells and regulates the progression of pancreatic cancer
}

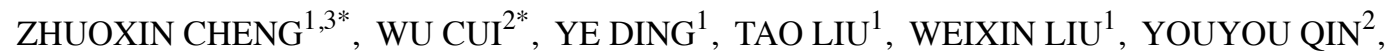 \\ WEIBIN XIA $^{1}$, JIAN XU ${ }^{1}$, YINGHAI ZHANG ${ }^{1}$ and XIAOMING ZOU $^{2}$ \\ ${ }^{1}$ Department of General Surgery, The First Affiliated Hospital of Jiamusi University, Jiamusi, Heilongjiang 154002; \\ ${ }^{2}$ Department of General Surgery, The Second Affiliated Hospital of Harbin Medical University, Harbin, Heilongjiang 150001; \\ ${ }^{3}$ Department of Microbiology, Harbin Medical University, Harbin, Heilongjiang 150081, P.R. China
}

Received April 6, 2014; Accepted July 8, 2014

DOI: $10.3892 /$ or.2014.3413

\begin{abstract}
Pancreatic cancer has become one of the most common types of cancer. It is believed that inhibiting the apoptosis of tumor cells as well as overgrowth of tumor cells accelerate the progression and development of cancer. However, the detailed mechanisms of pancreatic cancer progression remain to be fully elucidated. Although bone morphogenetic protein (BMP) families are crucial mediators in some types of cancer, whether BMP8B is involved in regulating the growth and apoptosis of pancreatic cancer cells and the progression of pancreatic cancer is not clear. In the present study, we found that the expression of BMP8B was downregulated in pancreatic cancer tissue compared with the normal tissue adjacent to the tumors. Moreover, the overexpression of BMP8B inhibited cell growth and promoted activation of caspase-3 and -9 , the decrease of mitochondrial membrane potential and cell apoptosis in PANC-1, while silencing the BMP8B gene expression with BMP8B shRNA exerted anti-apoptotic effects and boosted the growth of pancreatic cancer cells in BxPC-3. Therefore, we concluded that BMP8B mediates the survival of pancreatic cancer cells and regulates the progression of pancreatic cancer, making it a potential therapeutic target for pancreatic cancer.
\end{abstract}

\section{Introduction}

Pancreatic cancer is a leading cause of cancer-related mortality and an aggressive malignancy with mortality rates almost

Correspondence to: Dr Xiaoming Zou, Department of General Surgery, The Second Affiliated Hospital of Harbin Medical University, 246 Xuefu Road, Nangang, Harbin, Heilongjiang 150081, P.R. China

E-mail: xiaomingzou@126.com

*Contributed equally

Key words: BMP8B, apoptosis, pancreatic cancer, shRNA, overexpression identical to incidence rates (1). The curative therapies of pancreatic cancer have translated into $<5 \%$ (2). The diagnosis of pancreatic cancer represents a particularly bleak prognosis for patients and their families. At present, due to the non-specific presenting symptoms of pancreatic cancer, to diagnose pancreatic cancer at early stages is impossible. Surgical resection is the only curative option for pancreatic cancer patients, yet only $20 \%$ of patients present with early-stage operable tumors (3). Patients with unresectable disease consequently receive chemotherapy and radiotherapy, which, however, also do not result in longer survival (4). Therefore, improving therapeutic options and diagnostic tools for pancreatic cancer patients is anticipated. The genetic changes of pancreatic cancer patients are important in identifying molecules for the development of therapies. To improve the treatment of pancreatic cancer, innovative approaches including new targeted molecules are needed.

Cancer is a genetic disease caused by accumulation of oncogenes and tumor suppressor gene changes (5). Bone morphogenetic protein (BMP)-family members are divided into three subgroups based on their similar amino acid sequence, including the BMP2/4 group, osteogenic protein-1 (OP-1) group (BMP5, BMP6, BMP7 and BMP8) and BMP9/10 group (6). BMPs are well known to play critical roles in diverse developmental phases, which are frequently disrupted in cancer, and BMPs have, to date, gained increasing attention in cancer research. However, the studies were mainly carried out in the most studied tumor types, such as breast and prostate cancer and hepatocellular carcinoma (7-10). BMP2 and BMP9 are reported to play important roles in breast cancer cell growth, and BMP6 and BMP7 are also detected in breast cancer cell lines and patient samples (11-14). However, there are only a few studies on the function of BMP8 in the development of cancer, and only little information of BMP8 is related to the progression of pancreatic cancer.

In the present study, as there is currently not enough complete information on human BMP8A, we determined the roles of BMP8B in pancreatic cancer. We found the expression of BMP8B was downregulated in pancreatic cancer tissue compared with the normal tissue adjacent to the tumors. Moreover, we demonstrated that BMP8B serves as a key regulator in the apoptosis and survival of pancreatic cancer cells 
by knocking down BMP8B or by overexpression of BMP8B. Exploring the effects of BMP8B on cancer cell growth and survival may provide a novel potential target for pancreatic cancer therapy.

\section{Materials and methods}

Materials. The antibodies against BMP8B, Bcl-2, Bax, Bim and $\beta$-actin were purchased from Santa Cruz Biotechnology Inc., Santa Cruz, CA, USA. Kits of caspase- 3 and -9 activities, and LDH assay kit were from Beyotime Institute of Biotechnology (Haimen, China). All other reagents were from common commercial sources.

Cell line preparation and culture. BxPC-3 and PANC-1, two human pancreatic cancer cell lines, were obtained from the American Type Culture Collection (Rockville, MD, USA). Both cell lines were routinely cultured at $37^{\circ} \mathrm{C}$ with RPMI-1640 medium supplemented with $10 \%$ fetal calf serum, penicillin $(100 \mathrm{U} / \mathrm{ml})$ and streptomycin $(100 \mu \mathrm{g} / \mathrm{ml})$ in an incubator with $95 \%$ air and $5 \% \mathrm{CO}_{2}$.

Generation of BMP8B shRNA expression and overexpression lentivirus. One shRNA targeting human BMP8B and one scrambled shRNA (used as a negative control) were designed and synthesized by Shanghai GenePharma Co., Ltd., Shanghai, China. The resultant lentivirus containing BMP8B shRNA sequence and negative control sequence were termed BMP8B shRNA and NC, respectively. The lentivirus of BMP8B overexpression was also purchased from Shanghai GenePharma Co., Ltd. We termed the BMP8B overexpression lentivirus and blank vector BMP8B and vector, respectively.

Assessment of cell viability. The assessment of cell viability was determined by 3-[4,5-dimethylthiazol-2-yl]-2,5-diphenyltetrazolium bromide (MTT) assay. BxPC- 3 and PANC- 1 cells were split into a $96-$ well plate $\left(\sim 5 \times 10^{3} /\right.$ well $)$, and then subjected to growth arrest for $24 \mathrm{~h}$ before different treatments as the indicated groups. The cells were divided into negative control and BMP8B shRNA, as well as vector and BMP8B overexpression for $72 \mathrm{~h}$. After $96 \mathrm{~h}$ of incubation at $37^{\circ} \mathrm{C}$, the cells were incubated in a medium containing $0.5 \%$ MTT at $5 \mathrm{~g} / 1$ and $20 \mu \mathrm{l} /$ well for $4 \mathrm{~h}$, and MTT was a yellow mitochondrial dye and prepared in phosphate-buffered saline (PBS). After adding DMSO to the medium followed by incubation for $10 \mathrm{~min}$ at $37^{\circ} \mathrm{C}$, the MTT reaction was terminated, and then the absorbance was read by a spectrophotometer at $540 \mathrm{~nm}$. All experiments were carried out in triplicate and repeated thrice.

Crystal violet assay. Cells in different groups $\left(\sim 5 \times 10^{3} /\right.$ well $)$ were seeded into 6-well plates and cultured for 7 days and the medium was switched every 2-3 days. Subsequently, the cells were washed twice with pre-warmed PBS, and then cells remaining were stained for $2 \mathrm{~h}$ with a crystal violet solution ( $0.5 \%$ crystal violet, $20 \%$ methanol). After removal of the crystal violet solution, the plates were washed three times by immersion in a beaker filled with tap water. Plates were left to dry at $37^{\circ} \mathrm{C}$, and then the images were photographed by camera.
Measurement of caspase-3 activity. Caspase-3 activity was measured by its chromogenic caspase substrate cleavage. The protein samples were prepared as the indicated groups. Then, $\sim 50 \mu \mathrm{g}$ total proteins of every indicated group were added to the reaction buffer containing Ac-DEVD-pNA, incubated for $4 \mathrm{~h}$ at $37^{\circ} \mathrm{C}$, and the absorbance of yellow pNA cleavage from its corresponding precursors was measured by using a spectrometer at $405 \mathrm{~nm}$. The specific caspase-3 activity was normalized to total proteins of cell lysates, and expressed as fold of the baseline caspase activities of control cells.

Measurement of caspase- 9 activity. Caspase- 9 activity was measured as per the manufacturer's instructions. We measured the cleavage of Ac-LEHD-pNA, the chromogenic caspase substrates of caspase- 9 , and normalized the specific caspase- 9 activity to total proteins of cell lysates. Then, the specific caspase-9 activity was expressed as fold of the baseline caspase activities of control cells.

LDH assay. The activity of lactate dehydrogenase (LDH) release into the culture media was measured using a cytotoxicity detection kit. Percentage of injured cells in cultures is represented by the LDH activities of medium relative to total LDH activity after complete cell lysis. Briefly, a portion of culture medium was reacted with an equal volume of LDH substrate solution for $30 \mathrm{~min}$. The reaction was stopped by adding 5 volume of $0.1 \mathrm{M} \mathrm{NaOH}$, and absorbance was then measured at $440 \mathrm{~nm}$ in a spectrophotometer. Sister cultures were treated with $1 / 100$ volume of $10 \%$ Triton X-100 and incubated at $37^{\circ} \mathrm{C}$ for $30 \mathrm{~min}$. Total $\mathrm{LDH}$ activities were determined using medium containing Triton-lysed cellular supernatant.

Western blotting. The methodology was described in previous reports (15). Briefly, $5 \times 10^{5}$ cells were sonicated in RIPA buffer and homogenized. Debris was removed by centrifugation at $12,000 \mathrm{x} \mathrm{g}$ for $10 \mathrm{~min}$ at $4^{\circ} \mathrm{C}$. The samples containing $50 \mu \mathrm{g}$ protein were electrophoresed on polyacrylamide SDS gels, and transferred to polyvinylidene difluoride (PVDF) membranes. The membranes were blocked with $3 \%$ BSA, incubated with primary antibodies, and subsequently with alkaline phosphatase-conjugated secondary antibody. They were developed with 5-bromo-4-chloro-3-indolyl phosphate/nitro blue tetrazolium (Tiangen Biotech Co. Ltd., Beijing, China). Blots were also stained with anti- $\beta$-actin antibody as an internal control for the amounts of target proteins.

Real-time PCR. Real-time PCR (qPCR) was performed with an Applied Biosystems 7300 Fast Real-Time PCR System. Primers were specifically designed using Applied Biosystems Primer Express 3.0. The primer used for BMP8B was: forward, 5'-AGGTGGCTTCCTTATCTGCG-3' and reverse, 5'-ATGTGCCAACTCTGCTTCGT-3', with a product length of $165 \mathrm{bp}$ The specificity of the primers was confirmed with a BLAST program. Each $20 \mu 1$ reaction contained $1 \mathrm{X} \mathrm{SYBR}^{\circledR}$ Premix Ex Taq ${ }^{\mathrm{TM}}$ II, $10 \mu \mathrm{M}$ forward and reverse primers, $0.4 \mu \mathrm{l}$ ROX reference dye and $2 \mu 1$ of cDNA. ABI 7300 Sequence Detector (Perkin-Elmer Applied Biosystems) was programmed for the PCR conditions: $95^{\circ} \mathrm{C}$ for $30 \mathrm{sec}, 40$ cycles of $95^{\circ} \mathrm{C}$ for $5 \mathrm{sec}$ and $60^{\circ} \mathrm{C}$ for $31 \mathrm{sec}$, followed by routine melting curve analysis. Relative quantitation (RQ) of target gene expression 


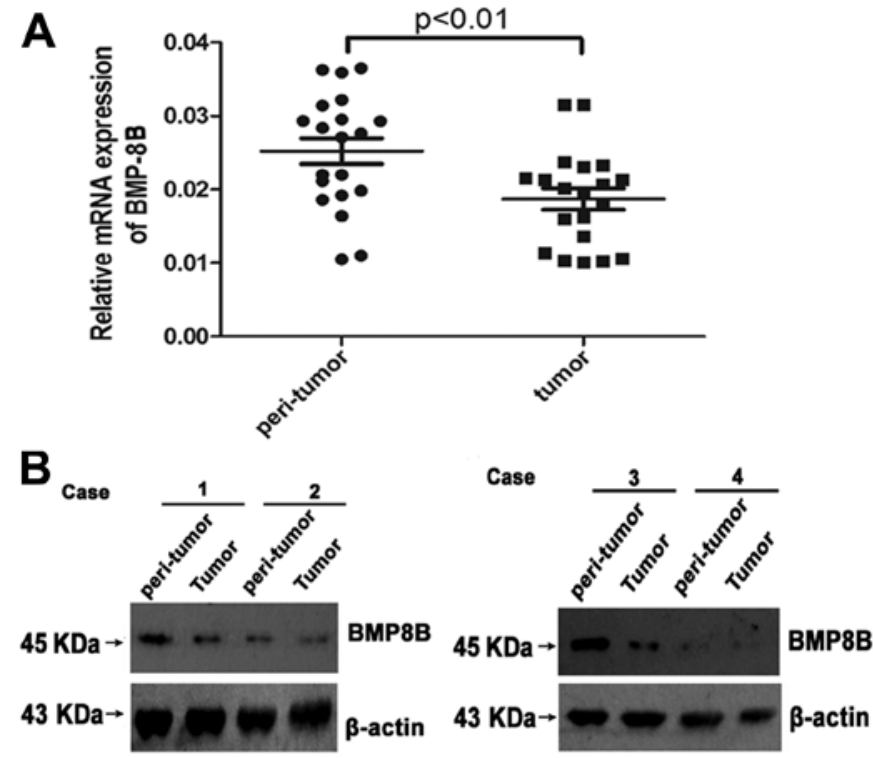

Figure 1. BMP8B is downregulated in the pancreatic cancer tissue. (A) The mRNA expression of BMP8B in pancreatic cancer tissue of 20 patients and the normal tissue adjacent to the tumors. (B) The protein expression of BMP8B in six patients with pancreatic cancer and their corresponding normal tissue adjacent to the tumors. All values are denoted as means \pm SEM $\left({ }^{*} \mathrm{p}<0.05\right)$.

was calculated by the $2^{-\Delta \Delta C T}$ method (16). The first step in the $\mathrm{RQ}$ analysis is to normalize target gene expression level to $\beta$-actin $(\Delta \mathrm{Ct})$. The second step is to compare the difference between normalized target gene expression between different samples $(\Delta \Delta \mathrm{Ct})$. Each experiment was repeated 2-3 times in 3-4 samples.

Statistical analysis. The results are expressed as the mean values \pm standard deviation, and a Student's t-test was used to evaluate statistical significance. A value of $<0.05(\mathrm{p}<0.05)$ was considered to indicate statistically significant differences.

\section{Results}

Expression of BMP8B is downregulated in the tissue of pancreatic cancer. To determine whether BMP8B is involved in the progression of pancreatic cancer, we first examined the expression of BMP8B in the patients of pancreatic cancer with western blotting and qPCR. We found that the protein and mRNA expression of BMP8B was significantly lower in pancreatic cancer tissue compared with the normal tissue adjacent to the tumors (Fig. $1 \mathrm{~A}$ and $\mathrm{B}, \mathrm{P}<0.05$ ). The results showed that BMP8B may play important roles in regulating the development of pancreatic cancer.

$B M P 8 B$ is overexpressed in PANC-1 and BXPC-3 is efficiently infected with BMP8B-shRNA. We then constructed the stably transfected cell lines of BMP8B overexpression in PANC-1 in order to further demonstrate that BMP-8 is associated with pancreatic cancer cell growth and survival. To confirm the transfection efficiency and to achieve the overexpressed cells of BMP8B, we examined the expression of BMP8B. As shown in Fig. $2 \mathrm{~A}$ and $\mathrm{B}$, the protein and mRNA expression of BMP8B were considerably increased in PANC-1.
A

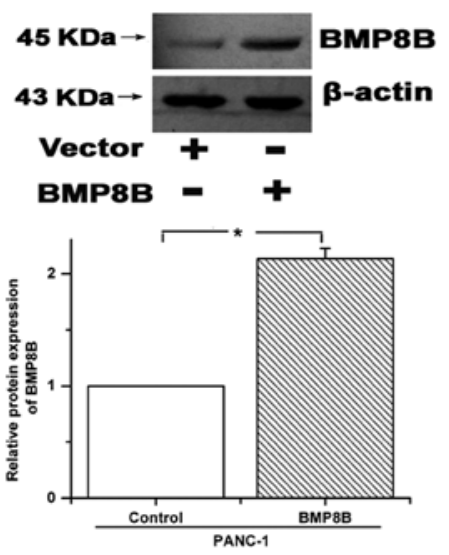

B

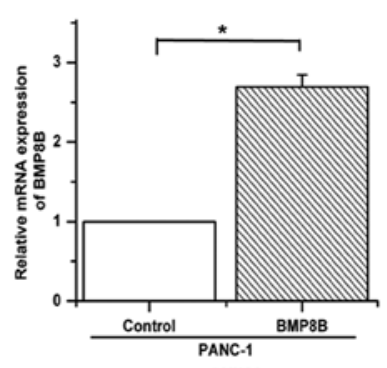

C

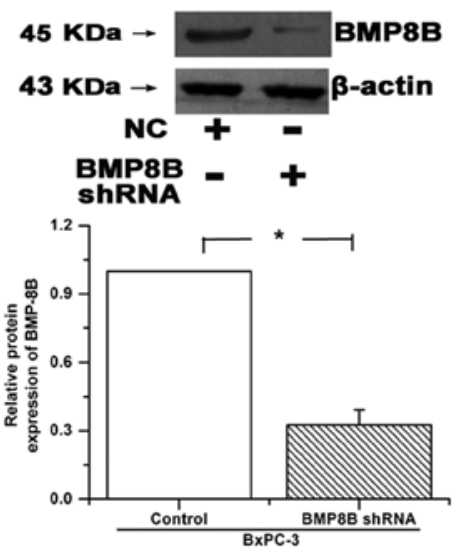

D

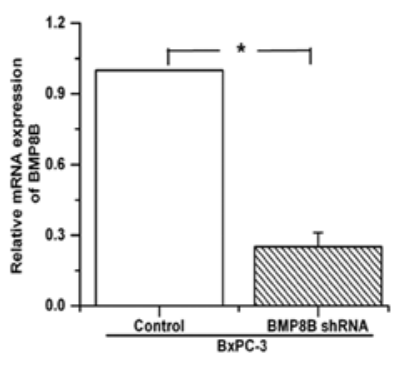

Figure 2. (A) PANC-1 infected with lentivirus vector and BMP8B in the lentivirus. We examined the protein expression of BMP8B with western blotting. BMP8B expression was significantly increased in the BMP8B overexpression group than in the vector group. (B) The mRNA expression of BMP8B was examined after infecting PANC-1 cells with vector and BMP8B. (C) BxPC-3 was treated with BMP8B shRNA or NC. Western blotting was applied to confirm the infection efficiency. The protein expression of BMP8B was significantly decreased by BMP8B shRNA in BxPC-3. (D) BMP8B shRNA reduced the mRNA expression of BMP8B as determined by qPCR. $\mathrm{NC}$, negative control; all values are denoted as means \pm SEM from three or more independent batches of cells $(* \mathrm{p}<0.05)$.

BxPC-3 was infected with BMP8B-shRNA to knock down BMP8B expression. We found the protein and mRNA expression of BMP8B was significantly decreased after applying BMP8B-shRNA in BxPC-3 compared to the negative control (NC) group (Fig. $2 \mathrm{C}$ and $\mathrm{D}, \mathrm{n}=3, \mathrm{p}<0.05$ ), indicating the adequate knocking down of the BMP- 8 gene by BMP8BshRNA.

Overexpression of BMP8B leads to cell growth arrest and death, and weakens the colony formation in pancreatic cancer cells. MTT was applied to determine the effects of BMP8B on cell growth. The results showed that the cell viability of PANC-1 was inhibited after overexpression of BMP8B (Fig. 3A, n=3, $\mathrm{p}<0.05$ ). Moreover, the release of $\mathrm{LDH}$, which occurs with cell death, was increased in BMP8B-overexpressed cells (Fig. 3B, $n=3, p<0.05$ ). The colony formation of tumor cells reflects the tumorigenicity of tumor cells. We found that overexpression of BMP8B resulted in the decreased colony formation activities 

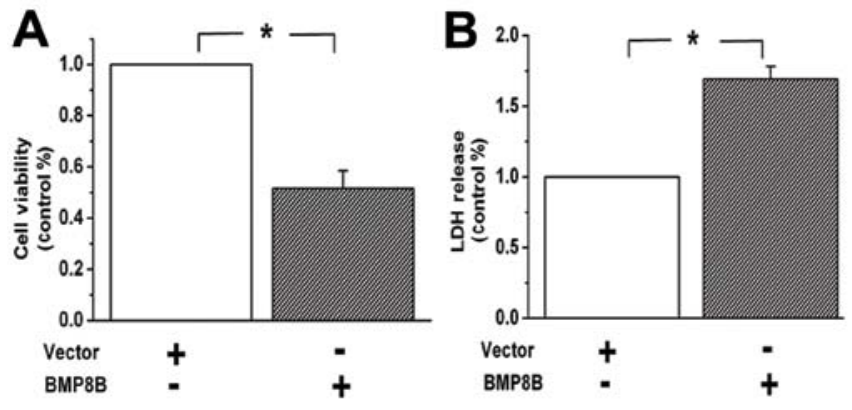

C

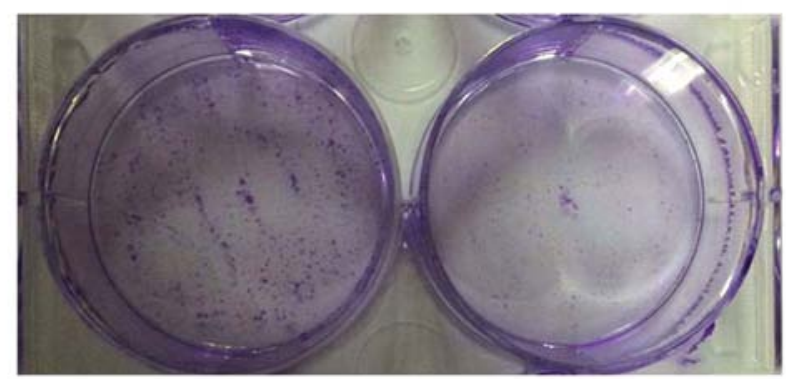

Figure 3. Growth and colony formation are inhibited by the overexpression of BMP8B in PANC-1. (A) The cell viabilities were suppressed by BMP8B overexpression as determined by MTT experiments. (B) Overexpression of BMP8B increased the release of LDH in PANC-1. (C) The colony formation of PANC-1 was inhibited by BMP8B overexpression. These results showed that overexpression of BMP8B leads to cell growth arrest and death, and weakens the colony formation in pancreatic cancer cells. All values are denoted as means \pm SEM from at least three separate experiments $\left(n=3,{ }^{*} p<0.05\right)$.

A
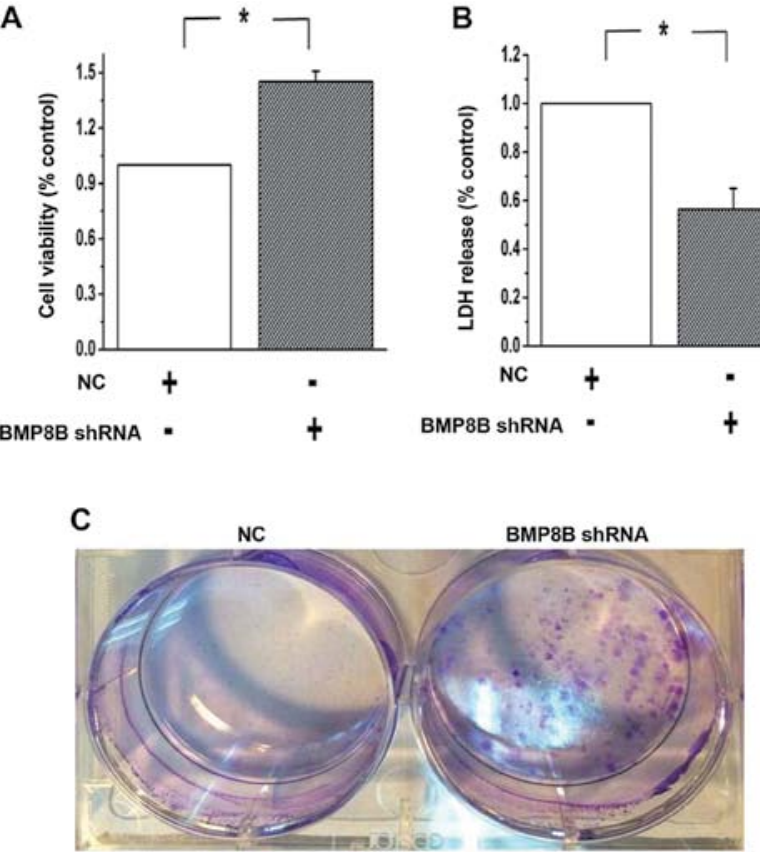

Figure 4. Knockdown of BMP8B expression stimulates cell growth and colony formation in BxPC-3. (A) MTT results show that silencing BMP8B expression with BMP8B shRNA boosted cell viability. (B) BMP8B shRNA inhibited the LDH release and cell death in BxPC-3. (C) Knockdown of $\mathrm{BMP} 8 \mathrm{~B}$ significantly promoted the colony formation in BxPC-3. NC, negative control. Values are denoted as means \pm SEM from three or more independent batches of cells $\left({ }^{*} \mathrm{p}<0.05\right)$.
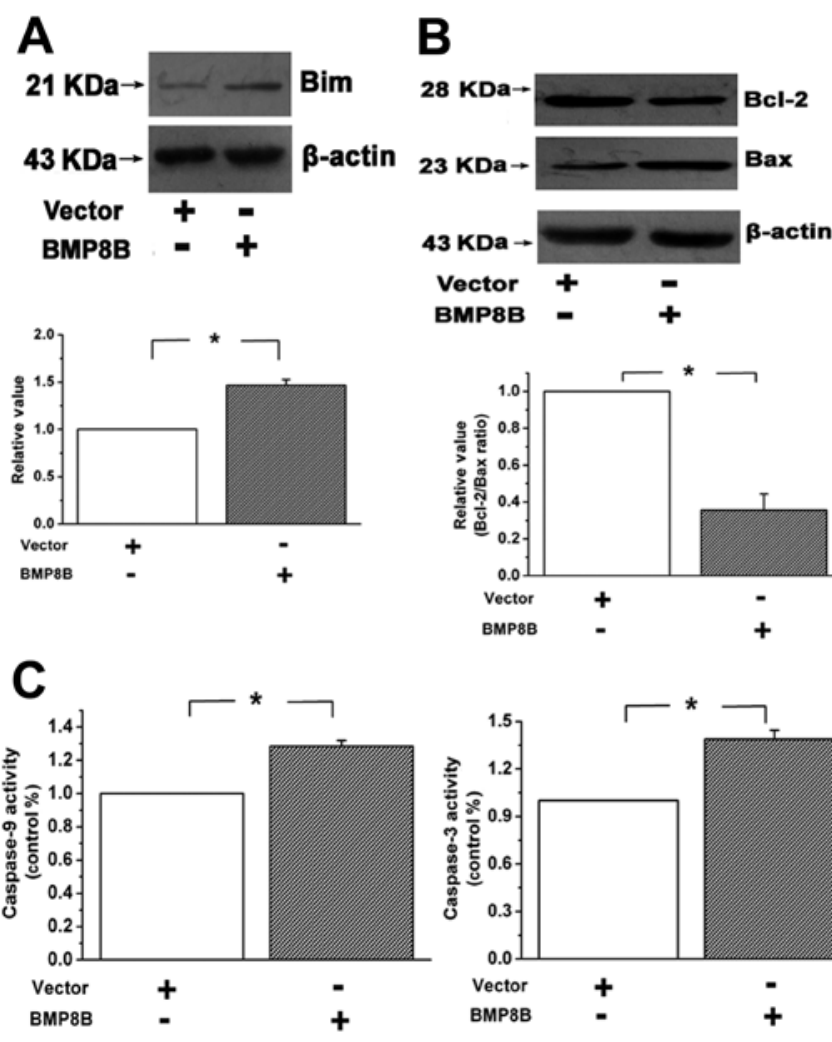

Figure 5. Overexpression of BMP8B regulates the expression of mitochondrial membrane proteins and activates caspase-9 and -3 . (A) The expression of Bim, the apoptotic protein, was upregulated by BMP8B in PANC-1. (B) Overexpression of BMP8B induced the expression of Bax and inhibited the $\mathrm{Bcl}-2$ expression, indicating that the ratio of $\mathrm{Bcl}-2 / \mathrm{Bax}$ was decreased by the treatment of BMP8B overexpression. (C) BMP8B overexpression increased the activities of caspase- 9 and -3 in PANC-1. All values are denoted as means \pm SEM from three independent batches of cells $\left(n=3,{ }^{*} p<0.05\right)$.

in PANC-1 (Fig. 3C, n=3, p<0.05). These results demonstrated that overexpression of BMP8B blocked the growth of pancreatic cancer cells.

Knockdown of BMP8B gene expression promotes cell growth and colony formation. We examined the cell growth and colony formation in BxPC-3 after silencing the BMP8B gene expression with BMP8B shRNA. As shown in Fig. 4, knocking down BMP8B expression increased cell growth and promoted colony formation, and inhibited the release of LDH in BxPC-3. The results were in accordance with the findings of Fig. 3.

$B M P 8 B$ overexpression induces the mitochondrial-dependent apoptosis through regulating $\mathrm{Bim} / \mathrm{Bcl}-2 / \mathrm{Bax}$ expression. $\mathrm{Bim}$, Bcl-2 and Bax are important molecules localized on mitochondrial outer membrane and control the stability of mitochondria. Bim and Bax are pro-apoptotic proteins and $\mathrm{Bcl}-2$ is an antiapoptotic protein. In our experiments, we found the expression of Bim and Bax was upregulated by BMP8B overexpression, and the overexpression of BMP8B blocked the expression of Bcl-2 in PANC-1 (Fig. 5A and B, n=3, p<0.05). Furthermore, caspase-3 and -9 are the key performers during the mitochondrial pathway apoptosis. We then examined whether BMP8B participated in regulating the activation of caspase- 3 and -9 . The results showed that the activation of caspase- 3 and -9 was 
A

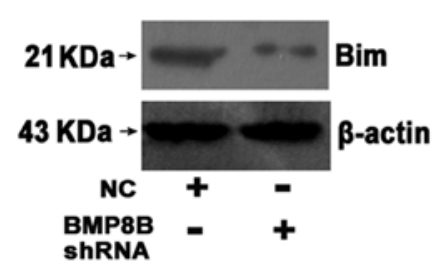

B
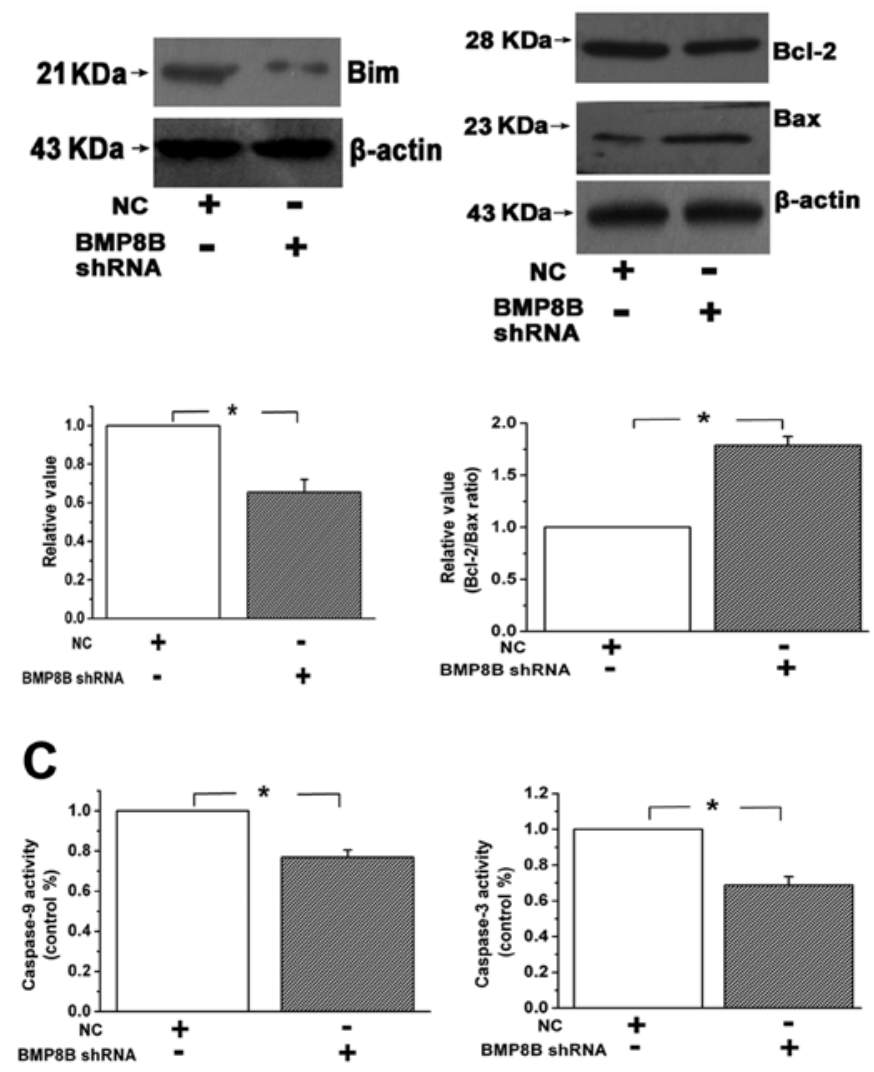

Figure 6. (A) Bim expression is inhibited by knocking down BMP8B expression. (B) Silencing BMP8B increased the ratio of Bcl-2/Bax in BxPC-3 (C) Caspase-3 and -9 activities were decreased by knocking down BMP8B expression. Values are denoted as means \pm SEM from at least three separate experiments $\left(n=3,{ }^{*} \mathrm{p}<0.05\right)$.

increased by BMP8B overexpression in PANC-1 (Fig. 5C, $n=3$, $\mathrm{p}<0.05)$. These results demonstrate that the overexpression of BMP8B triggers the mitochondrial-dependent apoptosis through regulating $\mathrm{Bim} / \mathrm{Bcl}-2 / \mathrm{Bax}$ expression.

The mitochondrial pathway of apoptosis is inhibited by decreasing the BMP8B expression. We also examined the activation of caspase- 3 and -9 and the expression of mitochondrial membrane proteins after knocking down BMP8B gene expression in BxPC-3 to further support our conclusion. Our results showed that silencing BMP8B gene induced $\mathrm{Bcl}-2$ expression and decreased the expression of Bim and Bax (Fig. 6A and B, $\mathrm{n}=3, \mathrm{p}<0.05)$. Moreover, the activities of caspase-3 and -9 were suppressed by BMP8B shRNA in BxPC-3 (Fig. 6C, $n=3$, $\mathrm{p}<0.05)$, indicating that the apoptosis is inhibited by knocking down BMP8B expression.

\section{Discussion}

It is well known that promoting tumor cell proliferation and inhibiting cell apoptosis both result in the overgrowth of tumor cells, which accelerates the progression and development of tumors. In the present study, we demonstrated that BMP8B is downregulated in pancreatic cancer tissue compared with the normal tissue adjacent to the tumors. Moreover, overexpression of BMP8B induced apoptosis and inhibited the growth in pancreatic cancer cells, and silencing BMP8B gene expression promoted pancreatic cancer cell survival and decreased apoptosis. We provide new evidence that BMP8B likely serves as a tumor suppressor gene to inhibit the growth of pancreatic cancer cells, and silencing BMP8B gene expression advances the progression of pancreatic cancer.

Mounting evidence indicates that an important feature of tumor cells is infinitely excessive growth and proliferation. Thus, examining the oncogene and tumor suppressor gene is helpful to relieve the progression of cancer and to provide potential therapeutic targets for treatment (17). Previous studies reported that BMP8B plays a positive role in promoting cell proliferation and tumor development (18). However, direct evidence that BMP8B is associated with advancing the progression of pancreatic cancer and BMP8B overexpression inhibiting the growth of pancreatic cancer cells is lacking. In the present study, we found that the protein and mRNA expression of BMP8B is decreased in pancreatic cancer tissue compared with the normal tissue adjacent to the tumors. Moreover, overexpression of BMP8B inhibited the growth and colony formation of PANC-1, and silencing the BMP8B gene expression promoted the colony formation and cell growth in BxPC-3. We believe that the inhibition of the BMP8B pathway is required for the survival of pancreatic cancer cells.

An important physiological change of the early events of the mitochondrial apoptosis pathway is mitochondrial dysfunction (19). In general, the mitochondrial dysfunction results from the expression change of the proteins, which are localized on the mitochondrial membrane and control the opening of mitochondrial membrane pores. Then, the release of cytochrome $c$ from the mitochondria into the cytoplasm induced by mitochondrial dysfunction activates caspase- 9 and -3 , and causes cell apoptosis (20). In the present study, we observed that the overexpression of BMP8B induced the expression of Bim and decreased the ratio of Bcl-2/Bax. On the contrary, knocking down BMP8B expression resulted in the increased ratio of $\mathrm{Bcl}-2$ to $\mathrm{Bax}$ and downregulated the expression of Bim. Moreover, caspase-3 and -9 were activated in BMP8Boverexpressed PANC-1, and silencing BMP8B expression inhibited the activation of caspase-3 and -9 in BxPC-3. In brief, we demonstrated that BMP8B protects against mitochondriadependent apoptosis in pancreatic cancer cells.

Although we confirmed the important roles of BMP8B in regulating pancreatic cancer cell survival, how the BMP8B pathway promotes pancreatic cancer development remains to be examined in further studies. In addition, it still needs to be determined whether the BMP8B pathway is also involved in regulating the death receptor pathway (the other important apoptosis pathway) in pancreatic cancer.

In conclusion, it has been demonstrated that BMP8B, which is downregulated in the tissue of pancreatic cancer, exerts inhibitive effects on the apoptosis of pancreatic cancer cells. These findings elucidate one possible mechanism of pancreatic cancer progression influenced by BMP8B, providing a novel potential therapeutic target for the treatment in the future.

\section{Acknowledgements}

This study was supported in part by grants from the Science and Technology Research Project of the Education 
Department of Heilongjiang Province (no. 12541814 to Z.X. Cheng), the Natural Science Foundation of Heilongjiang Province (no. H201373 to Z.X. Cheng), Jiamusi University Youth Foundation (q2013-024 to Z.X. Cheng), Heilongjiang Provincial Health Department Fund (2013-238 to Z.X. Cheng).

\section{References}

1. Danovi SA1, Wong HH and Lemoine NR: Targeted therapies for pancreatic cancer. Br Med Bull 87: 97-130, 2008.

2. Warshaw AL and Fernández-del Castillo C: Pancreatic carcinoma. N Engl J Med 326: 455-465, 1992.

3. Li D, Xie K, Wolff R and Abbruzzese JL: Pancreatic cancer. Lancet 363: 1049-1057, 2004.

4. Bardeesy N and DePinho RA: Pancreatic cancer biology and genetics. Nat Rev Cancer 2: 897-909, 2002.

5. Alarmo EL and Kallioniemi A: Bone morphogenetic proteins in breast cancer: dual role in tumourigenesis? Endocr Relat Cancer 17: R123-R139, 2010

6. Miyazono K, Kamiya Y and Morikawa M: Bone morphogenetic protein receptors and signal transduction. J Biochem 147: 35-51, 2010.

7. Kim IY and Kim SJ: Role of bone morphogenetic proteins in transitional cell carcinoma cells. Cancer Lett 241: 118-123, 2006.

8. Langenfeld EM, Kong Y and Langenfeld J: Bone morphogenetic protein 2 stimulation of tumor growth involves the activation of Smad-1/5. Oncogene 25: 685-692, 2006.

9. Piccirillo SG, Reynolds BA, Zanetti N, Lamorte G, Binda E, Broggi G, Brem H, Olivi A, Dimeco F and Vescovi AL: Bone morphogenetic proteins inhibit the tumorigenic potential of human brain tumour-initiating cells. Nature 444: 761-765, 2006.

10. Bleuming SA, He XC, Kodach LL, Hardwick JC, Koopman FA, Ten Kate FJ, van Deventer SJ, Hommes DW, Peppelenbosch MP, Offerhaus GJ, Li L and van den Brink GR: Bone morphogenetic protein signaling suppresses tumorigenesis at gastric epithelial transition zones in mice. Cancer Res 67: 8149-8155, 2007.

11. Arnold SF, Tims E and Mcgrath BE: Identification of bone morphogenetic proteins and their receptors in human breast cancer cell lines: importance of BMP2. Cytokine 11: 1031-1037, 1999.
12. Ren W, Sun X, Wang K, Feng H, Liu Y, Fei C, Wan S, Wang W, Luo J, Shi Q, Tang M, Zuo G, Weng Y, He T and Zhang Y: BMP9 inhibits the bone metastasis of breast cancer cells by downregulating CCN2 (connective tissue growth factor, CTGF) expression. Mol Biol Rep 41: 1373-1383, 2014.

13. Autzen P, Robson CN, Bjartell A, Malcolm AJ, Johnson MI, Neal DE and Hamdy FC: Bone morphogenetic protein 6 in skeletal metastases from prostate cancer and other common human malignancies. Br J Cancer 78: 1219-1223, 1998.

14. Alarmo EL, Pärssinen J, Ketolainen JM, Savinainen K, Karhu R and Kallioniemi A: BMP7 influences proliferation, migration, and invasion of breast cancer cells. Cancer Lett 275: 35-43, 2009.

15. Wang SJ, Gao Y, Chen H, Kong R, Jiang HC, Pan SH, Xue DB, Bai XW and Sun B: Dihydroartemisinin inactivates NF- $\kappa B$ and potentiates the anti-tumor effect of gemcitabine on pancreatic cancer both in vitro and in vivo. Cancer Lett 293: 99-108, 2010.

16. Livak KJ and Schmittgen TD: Analysis of relative gene expression data using real-time quantitative PCR and the $2^{-\Delta \Delta C_{\mathrm{T}}}$ method. Methods 25: 402-408, 2001.

17. Spender LC and Inman GJ: Developments in Burkitt's lymphoma: novel cooperations in oncogenic MYC signaling. Cancer Manag Res 6: 27-38, 2014

18. Mima K, Fukagawa T, Kurashige J, Takano Y, Uchi R, Ueo H, Matsumura T, Ishibashi M, Sawada G, Takahashi Y, Akiyoshi S, Eguchi H, Sudo T, Sugimachi K, Watanabe M, Ishii H, Mori M, Baba H, Sasako M and Mimori K: Gene expression of bone morphogenic protein $8 \mathrm{~B}$ in the primary site, peripheral blood and bone marrow of patients with gastric cancer. Oncol Lett 6 : 387-392, 2013.

19. Jung SH, Kang KD, Ji D, Fawcett RJ, Safa R, Kamalden TA and Osborne NN: The flavonoid baicalin counteracts ischemic and oxidative insults to retinal cells and lipid peroxidation to brain membranes. Neurochem Int 53: 325-337, 2008.

20. Correa F, Soto V and Zazueta C: Mitochondrial permeability transition relevance for apoptotic triggering in the post-ischemic heart. Int J Biochem Cell Biol 39: 787-798, 2007. 